\section{Cureus}

\title{
Pregnancy and Privacy in an Emergency Department: A Simulated Session
}

\author{
Holly Black ${ }^{1}$, Tia S. Renouf MD ${ }^{2}$, Michael H. Parsons ${ }^{3}$, Peter Rogers ${ }^{4}$, Adam Dubrowski ${ }^{5}$ \\ 1. Emergency Medicine, Memorial University of Newfoundland 2. Emergency Medicine, Memorial \\ University of Newfoundland/Tairawhiti Hospital, Gisborne, NZL 3. Emergency Medicine, Memorial \\ University of Newfoundland, St. John's, CAN 4. Discipline of Emergency Medicine, Memorial University of \\ Newfoundland 5. Health Sciences, University of Ontario Institute of Technology, Oshawa, CAN
}

$\square$ Corresponding author: Adam Dubrowski, adam.dubrowski@gmail.com Disclosures can be found in Additional Information at the end of the article

\section{Abstract}

The practice of emergency medicine requires that physicians make critical decisions under the pressures of both time and socially challenging situations. Ectopic pregnancy is one such scenario in which physicians must think and act quickly, while keeping in mind the complexities of discussing reproductive health issues in an environment where confidentiality is difficult to achieve. The following describes a simulation session in which learners are tasked with the integration of clinical decision-making and the maintenance of privacy and confidentiality.

Categories: Emergency Medicine, Medical Simulation, Obstetrics/Gynecology

Keywords: ectopic pregnancy, privacy, emergency medicine, reproductive health

\section{Introduction}

Simulation-based medical education (SBME) is a helpful teaching and learning tool in postgraduate emergency medicine training. The comprehensive and realistic perspective gained using simulation allows learners of all levels to practice both procedural and communication skills, the mastery of which may mitigate patient risk [1]. The following describes a uni-professional SBME session in which a group of emergency medicine residents manages a potentially life-threatening ectopic pregnancy, while maintaining patient privacy in the Emergency Department (ED). In an effort to provide the most realistic scenario, this SBME session is based on an actual case and highlights key features in the diagnosis and treatment of ectopic pregnancy. Details have been altered to maintain patient anonymity.

Received 09/27/2014 Review began 09/29/2014 Review ended 09/30/2014 Published 10/01/2014

\section{(C) Copyright 2014}

Black et al. This is an open access article distributed under the terms of the Creative Commons Attribution License CC-BY 3.0., which permits unrestricted use, distribution, and reproduction in any medium, provided the original author and source are credited.

\section{Ectopic pregnancy}

Ectopic pregnancy is defined as the abnormal implantation of an embryo in any site other than the intrauterine space. Risk factors include pelvic inflammatory disease, previous fallopian tube surgery, previous ectopic pregnancy, intrauterine device use, and assisted reproduction techniques [2]. Ruling out ectopic pregnancy is critical, as it is the leading cause of maternal death in the first trimester [3]. Patient history may vary with respect to abdominal pain, vaginal bleeding, and missed menses. Consequently, ectopic pregnancy should be considered in all females of childbearing age presenting with vaginal bleeding, abdominal pain, or signs or symptoms of intra-peritoneal bleeding, including shoulder tip pain, pre-syncope/syncope, tachycardia, or relative bradycardia due to vagal stimulation [4]. It is also essential that physicians know there is no reference range for beta human chorionic gonadotropin levels $(\beta-h C G)$ at which the location of a pregnancy can be determined [3]. Ectopic pregnancies often 
have a relatively low $\beta$-hCG and longer doubling times [4]. Transvaginal ultrasound has been found to the most accurate diagnostic tool for ectopic pregnancy [3].

\section{Privacy}

It is the ethical responsibility of emergency physicians to assure and maintain patient privacy and confidentiality despite challenges, such as structural layout of the ED [5] and the presence of patient families. Although often helpful and supportive, family presence may be unwanted by the patient; this may cause undue stress and complicate diagnosis and treatment [6]. Emergency medicine residents must learn to consider the patient-family dynamic, particularly when dealing with the social complexities of reproductive health in the face of a potentially critical illness.

\section{Technical Report}

\section{Method}

Prior to development of this simulation scenario, the clinical case and its pertinent learning objectives were thoroughly discussed and identified by experts in the field. Early identification of learning objectives ensures that crucial learning points are addressed and the case is of an appropriate level of difficulty for the learners [7]. Wiseman and Snell's "Deteriorating Patient Scenario" (DPS) was used as the basis for this simulation session. The DPS method was developed based on the premise that it is difficult to reproduce the need to 'think on one's feet' which is required in complex clinical environments and situations. The DPS method is an inexpensive, portable, and rapidly created simulation that reproduces - in real time - the roles, decisions, and emotions involved in health professional-patient interactions; the reasoning skills required to manage a 'deteriorating patient' are also made explicit [8].

\section{Educators}

The scenario was led by a qualified emergency room physician who was familiar with both the challenges associated with working in a busy emergency department and the management of a patient presenting with ectopic pregnancy. Prior to the session, the educator was familiarized with how to run the simulation case using the DPS methodology. The algorithm depicted in Figure 1 was developed as a guide for this educator, as well as others in our institution who wish to use a similar method. The algorithm presented in Figure 1 was modified from Wiseman and Snells' [8] "clinical teacher's perspective during a DPS session" figure, to better suit this simulation session. A stepwise, objectives-based approach to patient management was devised and given to the educator (Table 1). During this session, the educator communicated the "Additional Data", "Vital Signs", and "Lab/Diagnostic Imaging" sections of Table 1 to the learner. Areas for teaching and review were documented throughout the exercise. In order to create a safe space in which learners felt comfortable making errors, several "HINTS" and "PROMPTS" were also embedded in the "additional data" section of Table 1 . These encouraged the learner to change his or her management, if necessary, and ensured provision of adequate time to think through the clinical situation [8]. 


\section{Cureus}

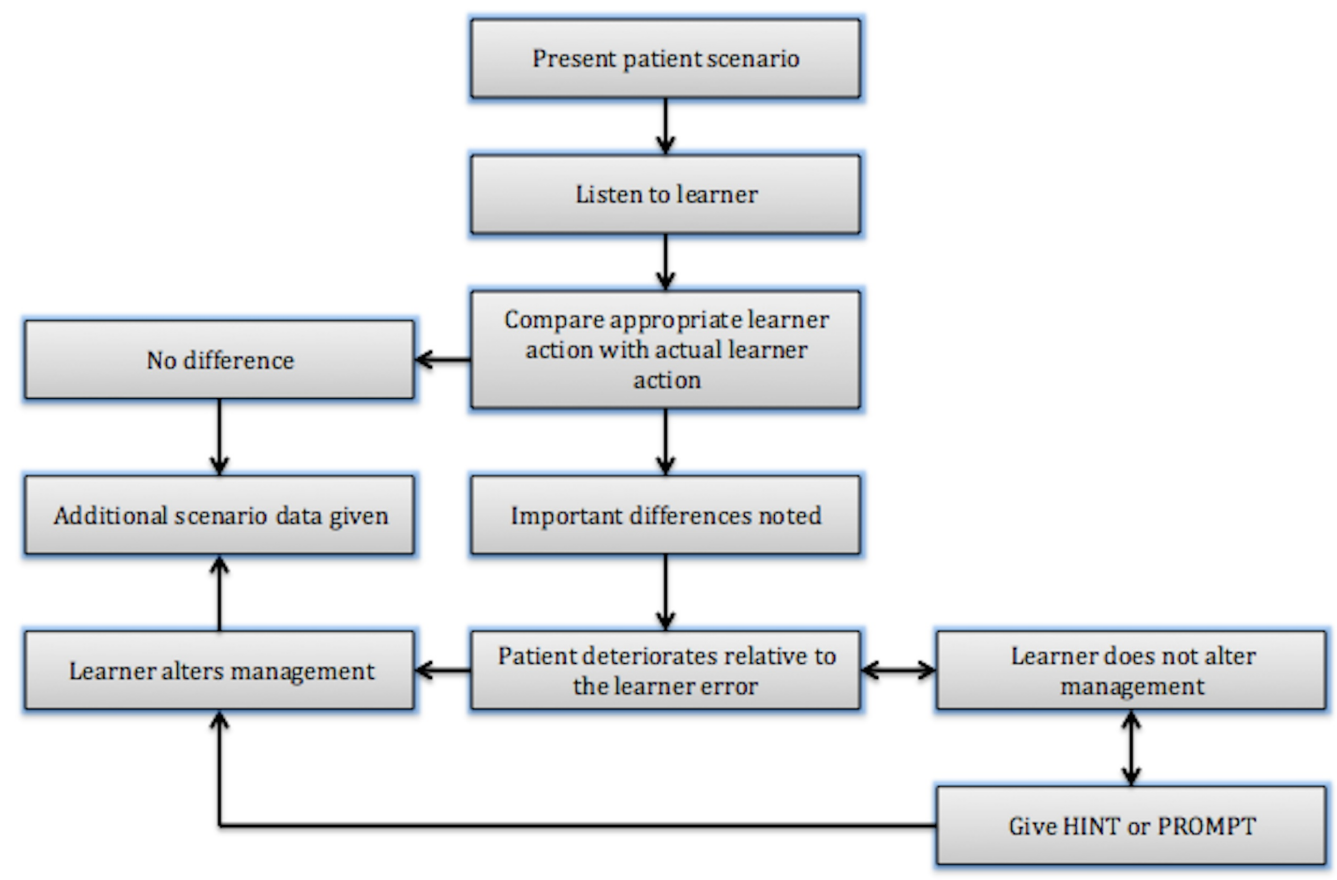

FIGURE 1: Educators Perspective During Simulated Session

This algorithm has been modified from Wiseman and Snell's [8] "clinical teachers perspective during a DPS session" figure, to better suit this simulation session.

\section{Scenario}

You are an emergency room physician at a tertiary care center. A 25-year-old ambulatory female presents to the department with right lower quadrant abdominal pain. The triage nurse escorts her to a stretcher. The patient is accompanied by her mother. The only information provided by the triage nurse is as follows: BP 120/72, HR 88, RR 16, T $36^{6}$, GCS 15 . No standing orders have been initiated.

Begin Scenario- Learner enters the patient's room

Objective 1: Airway, Breathing, Circulation
Additional Data
Vital Signs
Appropriate Learner
Action
Patient is in no distress; alert and oriented, the patient's mother is insisting her daughter has appendicitis.
Vital signs:
Takes a history and Normal performs abdominal exam.

Objective 2: Rule out pregnancy-related pathology in females of child bearing age who present with abdominal pain.

\section{Additional Data}

Educator as patient: The pain started about a week ago. It is constant in nature, does not radiate, and there are no provocative or palliative features. The patient insists there is no chance she could be pregnant. On exam the patient's abdomen is soft, tender to palpation in the right lower quadrant,
Vital Signs

Appropriate Learner Action

Orders: complete blood

Vital signs: Normal count, electrolytes, BUN, creatinine, liver function 


\section{Cureus}

negative McBurneys's point tenderness, negative psoas sign, no rebound tenderness. tests, INR and

urinalysis/pregnancy test

Laboratory/ECG/ Diagnostic Imaging Results

If Ordered: Urinalysis/pregnancy Test: Positive

If learner does not order pregnancy test. PROMPT: The patient deteriorates stating, "I don't feel well" and complains of pain to right shoulder.

If learner still does not order pregnancy test. HINT: Educator as nurse "would you like to urine sample taken?"

\author{
Vital signs \\ deteriorate: \\ BP 98/60, \\ HR 126, \\ RR 22 \\ Manages hypotension and \\ tachycardia with large bore \\ Vital signs \\ IVs and NS boluses \\ deteriorate: \\ Orders: type and screen \\ HR 140 , \\ RR 24
}

Upon recognition of the importance of ruling out pregnancy-related pathology in females of child bearing age presenting with abdominal pain, the learner is informed the urine pregnancy test is positive.

Objective 3: Managing patient privacy in the Emergency Department

\section{Additional Data}

If learner requests privacy: patient gives full history, explaining she had been seen in the ED 2 days ago for a miscarriage. At the time she had a bedside ultrasound preformed with no definitive intrauterine pregnancy and her $\beta$-hCG was $800 \mathrm{IU} / \mathrm{L}$. Obstetrics was consulted, follow-up was initiated with them, and the patient was instructed to return to ED if she had concerns or condition worsened.

The learner does not recognize the importance of privacy. PROMPT: Patient deteriorates and does not give full history. Mother becomes angry.

The learner still does not recognize the importance of privacy. HINT: Educator as nurse "Doctor she insisted she was not pregnant and I suspect the patient does not feel comfortable discussing the issue with her mother present"

$\begin{array}{ll}\text { Vital Signs } & \text { Appropriate Learner } \\ & \text { Action }\end{array}$

Vital signs: Asks mother for privacy BP 100/60, and explains to patient that HR 96, RR her urine pregnancy test is 22 positive.

Upon recognition of the importance of maintaining privacy in the emergency department the learner is provided with a full history and any abnormal vital signs stabilize. The educator also provides the learner with a bedside ultrasound video clip illustrating findings at the first visit. (See Video 1)

Objective 4: Managing abdominal pain in the pregnant (< than 20 weeks) patient

\section{Additional Data}

Vital Signs

Vital signs:
Appropriate Learner Action

Orders serum $\beta$-hCG. 


\section{Cureus}

Patient agrees to further testing

102/60, HR bedside ultrasound, orders

104, RR 22 transvaginal ultrasound.

Urgent consult

to Obs/Gyne

Laboratory/ECG/ Diagnostic Imaging Results

If Ordered: $\beta$-hCG remains elevated at $650 \mathrm{IU} / \mathrm{L}$. Bedside ultrasound: (See Video 2). If the learner also decides to scan right upper quadrant during repeat bedside ultrasound: (See Video 3)

End Scenario

\section{TABLE 1: A Stepwise, Detailed Scenario Template}

Blood Pressure (BP) Heart Rate (HR) Respiratory Rate (RR) Temperature (T) Glasgow Coma Scale (GCS)

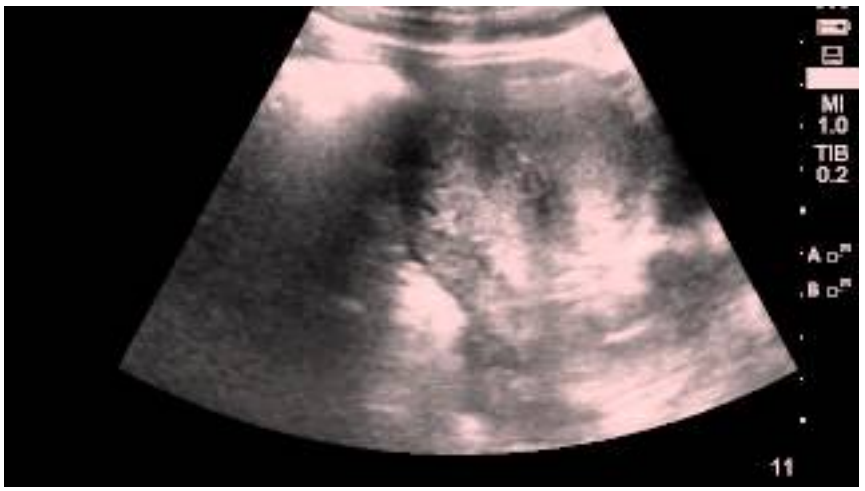

\section{VIDEO 1: Bedside Ultrasound Illustrating Findings During First Visit}

This video demonstrates a longitudinal view of the uterus with bladder-uterine juxtaposition. An intrauterine gestational sac is not definitively seen. A diagnosis of NDIUP (non-diagnostic intrauterine pregnancy) should be made.

View video here: http://youtu.be/q4BuPzi5uaA

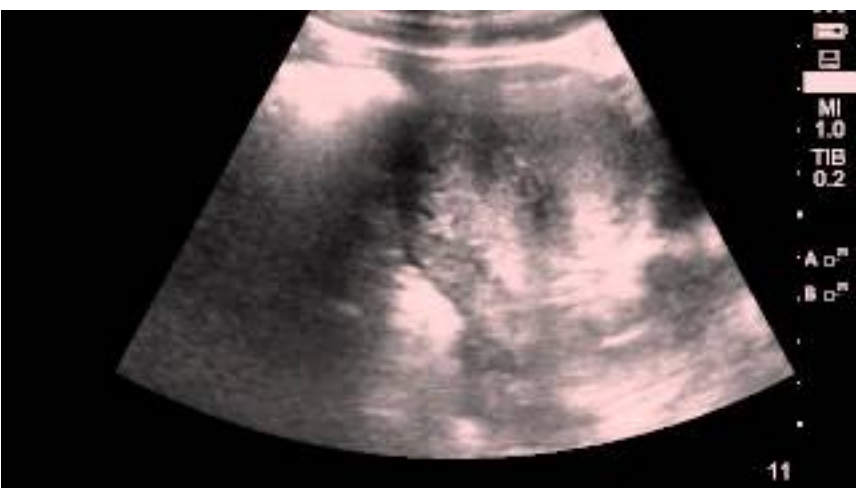

VIDEO 2: Bedside Ultrasound Illustrating Findings During Second Visit

This video demonstrates a longitudinal view of the uterus with bladder-uterine juxtaposition. An 


\section{Cureus}

intrauterine gestational sac is not definitively seen. A diagnosis of NDIUP (non-diagnostic intrauterine pregnancy) should be made. On careful inspection, some pelvic free fluid is visible. View video here: http://youtu.be/8akfm6QOMe8

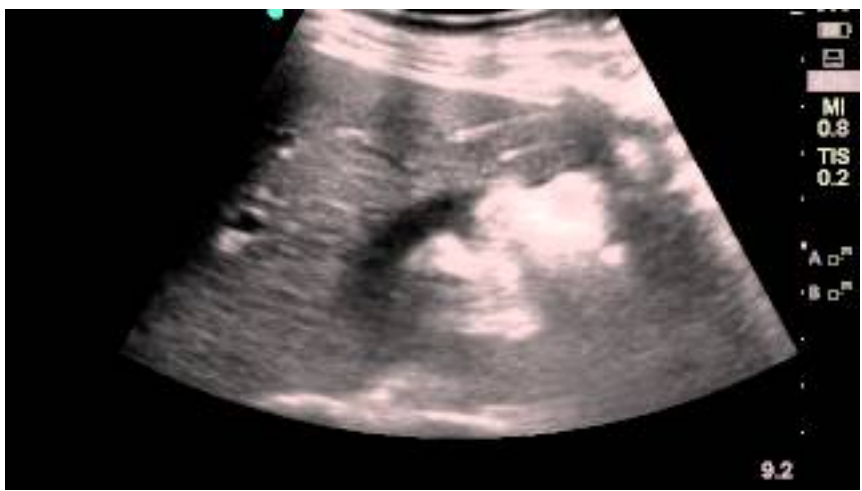

\section{VIDEO 3: Bedside Ultrasound of Right Upper Quadrant Illustrating Findings During Second Visit}

This video demonstrates free fluid in the hepato-renal space

View video here: http://youtu.be/Gs9tcJLrmis

\section{Simulator}

The simulation training session was conducted in a classroom. Audiovisual equipment was used to display the videos embedded in Table 1. One of the strengths of the DPS method as a pedagogic tool is its emphasis on the content of the session and the on-the-fly adjustment of the scenario to complement the learners' strengths and address weaknesses, rather than the simulation technology used. This session can also be adapted for use in a simulation lab using a high-fidelity mannequin simulator. The "Additional Data", "Vital Signs", and "Lab/Diagnostic Imaging" are easily formatted for use in a simulation lab.

\section{Learners}

The scenario was prepared for emergency medicine residents in their third and final year of training. The scenario was designed in such a way that it was suitable for either an individual learner or a group of three learners. One or several learners can work their way through this session, responding to the information given by the educator.

\section{Pre-briefing}

Before commencing the session, learners were presented with several learning objectives. This ensured that the learners are clearly cognizant of what was to be covered during the session [7]. The learning objectives were congruent with those presented in Table 1, but were kept nonspecific in order to avoid prematurely disclosing too much information about the scenario. This also permitted teaching about errors that may be made during the session.

The learning objectives were:

1) Recognition and management of a stable versus unstable patient,

2) Recognition of the challenges associated with maintaining privacy in the Emergency Department, 
3) Management of abdominal pain.

\section{Discussion}

\section{Case selection}

Excellent care of any ED patient depends on an emergency physician's ability to quickly diagnose and treat urgent pathology, while managing competing priorities in a busy department. This session, modified for teaching purposes, was based on an actual case in which a female of childbearing age presented to the ED accompanied by her mother. Despite the patient's allowing her mother to be present, she was hesitant to give a thorough reproductive history. This omission made the diagnosis of a life-threatening condition difficult. As was the case in the actual clinical presentation, the priority embedded in this simulation was to diagnose ectopic pregnancy; the challenge was to do so without violating patient privacy and confidentiality.

\section{Debrief}

Following the simulation session, the case was reviewed with the trainees following the framediscovery model and self-reflective approach to debriefing. During this debrief, individual learners were encouraged to reflect on their own experience. Self-reflection is essential in SBME [9] as it encourages physicians to recognize their own errors, which can result in improved practice [10]. During the debrief, knowledge gaps noted during the session were discussed. The debriefer-to-learner ratio was 1:1, ensuring learners felt free to openly discuss this aspect of their simulation experience. It can be challenging for educators to provide this kind of objective feedback while maintaining a mentoring and supportive relationship with learners. Feedback was and must be given with care, ensuring it is both non-judgmental and constructive [10]. It is essential for learners to know that mistakes are normal and expected in SBME [11]. It was assumed the learner had a well-meaning rationale for their actions, allowing the instructor to use their expertise to explore this rationale, thus making the learning more individualized and meaningful [10].

\section{Conclusions}

This paper describes a simulation session in which the correct management of abdominal pain was partly dependent on the learner's ability to recognize the importance of maintaining privacy in the setting of a busy emergency department. The DPS method [8] used here teaches both of these key concepts using low fidelity SBME, enabling execution of this case in settings lacking expensive simulation equipment.

\section{Additional Information}

\section{Disclosures}

Human subjects: All authors have confirmed that this study did not involve human participants or tissue. Animal subjects: All authors have confirmed that this study did not involve animal subjects or tissue. Conflicts of interest: In compliance with the ICMJE uniform disclosure form, all authors declare the following: Payment/services info: All authors have declared that no financial support was received from any organization for the submitted work. Financial relationships: All authors have declared that they have no financial relationships at present or within the previous three years with any organizations that might have an interest in the submitted work. Other relationships: All authors have declared that there are no other relationships or activities that could appear to have influenced the submitted work.

\section{Acknowledgements}


This project was supported by Tuckamore Simulation Research Collaborative and Emergency Medicine Education Committee, Memorial University of Newfoundland. Thanks to Dr. Wade Young for sharing his cases. Thanks to Sabrina Alani for manuscript preparation and graphics creation.

\section{References}

1. Lateef F: Simulation-based learning: Just like the real thing. J Emerg Trauma Shock. 2010, 3(4):348-52.

2. Kumar V, Abbas A, Fausto N, Aster J: Robbins and Cotran Pathologic Basis of Disease . aunders Elseveir, Philadelphia, PA; 2004.

3. Crochet JR, Bastian LA, Chireau MV: Does this woman have an ectopic pregnancy?: The rational clinical examination systematic review. JAMA. 2013, 309(16):1722.

4. Krause RS, Janicke DM, Cydulka RK: Chapter 101. Ectopic Pregnancy and Emergencies in the First 20 Weeks of Pregnancy. Tintinalli's Emergency Medicine: A Comprehensive Study Guide, 7e. Tintinalli JE, Stapczynski J, Ma O, Cline DM, Cydulka RK, Meckler GD, T (ed): McGraw-Hill, New York, NY; 2011.

5. Barlas D, Sama AE, Ward MF, Lesser ML: Comparison of the auditory and visual privacy of emergency department treatment areas with curtains versus those with solid walls. Ann Emerg Med. 2001, 38(2):135-9.

6. Moskop JC, Marco CA, Larkin GL, Geiderman JM, Derse AR: From hippocrates to HIPAA: Privacy and confidentiality in emergency medicine--part II: Challenges in the emergency department. Ann Emerg Med. 2005, 45(1):60-7.

7. Cannon-Bowers JA: Recent advances in scenario-based training for medical education . Curr Opin Anaesthesiol. 2008, 21(6):784-9.

8. Wiseman J, Snell L: The deteriorating patient: A realistic but 'low-tech' simulation of emergency decision-making. Clin Teach. 2008, 5(2):93-7.

9. Fanning RM, Gaba DM: The role of debriefing in simulation-based learning. Simul Healthc. 2007, 2(2):115-25.

10. Rudolph JW, Simon R, Rivard P, Dufresne RL, Raemer DB: Debriefing with good judgment: Combining rigorous feedback with genuine inquiry. Anesthesiol Clin. 2007, 25(2):361-76.

11. Rudolph JW, Foldy EG, Robinson T, Kendall S, Taylor SS, Simon R: Helping without harming: The instructor's feedback dilemma in debriefing--a case study. Simul Healthc. 2013, 8(5):30416. 